\title{
Plantação de árvores com alunos do Ensino Médio como incentivo à sustentabilidade e responsabilidade social com o meio ambiente
}

Trees planting with High School students as an incentive to sustainability and social responsibility for the environment

Plantar árboles con estudiantes de Bachillerato como incentivo à la sostenibilidad y responsabilidad social por el medio ambiente

Henrique Rodrigues Silva ORCID: https://orcid.org/0000-0001-9137-5382 Universidade Estadual de Alagoas, Brasil E-mail: henrique.biologia1996@gmail.com

Diego Jorge da Silva ORCID: https://orcid.org/0000-0003-0974-2900 Universidade Federal de Alagoas, Brasil E-mail:diegojorge4895@gmail.com

Daniel de Souza Santos ORCID: https://orcid.org/0000-0001-6230-2985 Universidade Estadual de Alagoas, Brasil E-mail: daniel.biologo14@gmail.com

Allan Marcos da Silva

ORCID: https://orcid.org/0000-0002-4500-211X Universidade Estadual de Alagoas, Brasil E-mail: alllanmarcos05@gmail.com Larissa Santos Silva

ORCID: https://orcid.org/0000-0003-2398-0454 Universidade Estadual de Alagoas, Brasil E-mail: laryssa_santos2@hotmail.com

Estéfany Cabral dos Santos ORCID: https://orcid.org/0000-0002-7723-8039 Universidade Estadual de Alagoas, Brasil

E-mail: estefany_cabra10102@hotmail.com

Deyse Karoline dos Santos Trindade ORCID: https://orcid.org/0000-0003-4156-7508 Universidade Estadual de Alagoas, Brasil E-mail: deysekt@outlook.com

Rosany Raquel de Almeida Fonseca ORCID: https://orcid.org/0000-0002-5077-1802 Universidade Estadual de Alagoas, Brasil E-mail: rosanymotta123.rm@gmail.com

Iracema Raquel Santos Bezerra

ORCID: https://orcid.org/0000-0002-5612-4884 Universidade Federal dos Vales do Jequitinhonha e Mucuri, Brasil

E-mail: iracemaraquel@ufvjm.edu.br

Ana Riquelle Barbosa da Silva ORCID: https://orcid.org/0000-0002-8992-0609 Universidade Estadual de Alagoas, Brasil E-mail: anariquelli@gmail.com

Mariana dos Santos

ORCID: https://orcid.org/0000-0002-5892-2695 Universidade Federal de Alagoas, Brasil E-mail: santosmariana1112@gmail.com Josefa Eleusa da Rocha

ORCID: https://orcid.org/0000-0001-8175-1305 Universidade Estadual de Alagoas, Brasil E-mail: eleusa.rocha@uneal.edu.br

\section{Resumo}

As árvores urbanas tornaram-se um elemento fundamental das paisagens e composição do verde urbano, sendo essenciais na manutenção à qualidade ambiental das cidades, praças e escolas, interferindo significativamente nas microclimáticas condições. Deste modo, a arborização bem planejada é muito importante, pois existem vários benefícios 
independentemente do porte da cidade, pois estão condicionados à qualidade de vida e de seu planejamento, caso contrário, passa a ter um caráter de remediação, à medida que tenta se encaixar dentro das condições já existentes e solucionar problemas de toda ordem. O objetivo da pesquisa foi conscientizar os alunos que o plantio de árvores é importante, inclusive no ambiente escolar e na comunidade ao redor da escola, para que possa haver mais compromisso com o meio que se deparou. Assim, foi realizado um projeto com alunos de $1^{\circ}$ ano do Ensino Médio vespertino, da Escola Estadual de Educação Básica Pedro Joaquim de Jesus, localizada no município de Teotônio Vilela, Alagoas, em novembro de 2018. Com base nas perguntas realizadas aos alunos foi possível constatar que o conhecimento dos mesmos sobre a importância da arborização, eram básicos. No entanto, ao longo da realização do projeto, a concepção dos alunos com relação a importância das plantas mudou, diante a ação do projeto. Contudo, o trabalho realizado possibilitou vivenciar uma experiência dispondo-se do conhecimento do alunado diante da temática sobre a importância das plantas no meio em que eles convivem, ao nosso ecossistema, conscientizando-os do cuidado, manutenção e preservação o meio ambiente e saúde humana, a natureza.

Palavras-chave: Conscientização; Educação; Qualidade ambiental.

\begin{abstract}
Urban trees have become a fundamental element of landscapes and urban green composition, being essential in maintaining the environmental quality of cities, squares and schools, significantly interfering with microclimatic conditions. Thus, well-planned afforestation is very important, as there are several benefits regardless of the size of the city, as they are conditioned to the quality of life and its planning, otherwise, it starts to have a remedial character, as it tries to fit. within the existing conditions and solve problems of all kinds. The objective of the research was to make students aware that planting trees is important, including in the school environment and in the community around the school, so that there can be more commitment to the environment that they have come across. Thus, a project was carried out with 1st year students of afternoon high school, from the Pedro Joaquim de Jesus State School of Basic Education, located in the municipality of Teotônio Vilela, Alagoas, in November 2018. Based on the questions asked to the students, it was possible verify that their knowledge about the importance of afforestation was basic. However, over the course of the project, the students' conception of the importance of plants changed, due to the action of the project. However, the work carried out made it possible to experience an experience by providing the students with knowledge on the theme of the importance of plants in the environment in which they live, in our ecosystem, making them aware of the care, maintenance and preservation of the environment and human health, the nature.
\end{abstract}

Keywords: Awareness; Education; Environmental quality.

\title{
Resumen
}

Los árboles urbanos se han convertido en un elemento fundamental del paisaje y la composición del verde urbano, siendo imprescindibles en el mantenimiento de la calidad ambiental de las ciudades, plazas y escuelas, interfiriendo significativamente en las condiciones microclimáticas. Así, la forestación bien planificada es muy importante, ya que existen varios beneficios independientemente del tamaño de la ciudad, ya que están condicionados a la calidad de vida y su planificación, de lo contrario, comienza a tener un carácter remediador, ya que intenta encajar dentro de las condiciones existentes y solucionar problemas de todo tipo. El objetivo de la encuesta era concienciar a los estudiantes de que plantar árboles es importante, incluso en el entorno escolar y en la comunidad alrededor de la escuela, para que pueda haber un mayor compromiso con el medio ambiente con el que se han encontrado. Así, se llevó a cabo un proyecto con alumnos de 1er año de bachillerato vespertino, de la Escuela Estatal de Educación Básica Pedro Joaquim de Jesús, ubicada en el municipio de Teotônio Vilela, Alagoas, en noviembre de 2018. A partir de las preguntas formuladas a los alumnos, se pudo constatar que su conocimiento sobre la importancia de la forestación era básico. Sin embargo, a lo largo del proyecto, la concepción de los estudiantes sobre la importancia de las plantas cambió, dada la acción del proyecto. Contudo, o trabalho realizado possibilitou vivenciar uma experiência dispondo-se do conhecimento do alunado diante da temática sobre a importância das plantas no meio em que eles convivem, ao nosso ecossistema, conscientizando-os do cuidado, manutenção e preservação o meio ambiente e saúde humana, la naturaleza.

Palabras clave: Conciencia; Educación; Calidad del medio ambiente.

\section{Introdução}

As árvores urbanas tornaram-se um elemento fundamental das paisagens urbanas e são fundamentais para a composição do verde urbano, sendo assim um papel essencial na manutenção à qualidade ambiental das cidades, praças e escolas, interferindo significativamente nas microclimáticas condições. Nas cidades, a necessidade de espaços arborizados é reforçada pela escassez de verde adequado que é uma das estratégias para melhorar a qualidade de vida nas áreas urbanas e na maioria dos bairros o espaço para o plantio de árvores é limitado apenas às calçadas (Frigeri et al., 2017). 
Arborização bem planejada é muito importante, pois existem vários benefícios independentemente do porte da cidade, pois estão condicionados à qualidade de vida e de seu planejamento, caso contrário, passa a ter um caráter de remediação, à medida que tenta se encaixar dentro das condições já existentes e solucionar problemas de toda ordem (Bonametti, 2020).

Segundo Avrella et al. (2014), a primeira ação necessária para o planejamento da arborização ou replanejamento, no caso de cidades já arborizadas, é o diagnóstico das áreas verdes existentes. Assim, estudos que caracterizem a arborização são relevantes, uma vez que permitem conhecer o patrimônio verde, subsidiando a definição de política de administração e estratégias de manejo em longo prazo, como o estabelecimento de previsões orçamentárias para o futuro, a preparação de um programa de gerenciamento dos indivíduos cultivados, a definição de prioridades nas intervenções, a localização de áreas para plantio e de plantas com necessidade de tratamento ou remoção.

Além de todos os benefícios de arborização, atribui-se ao homem a responsabilidade de paisagismo, transformando diferentes grupos culturais correspondendo a uma visão natural e agradável capazes de fazer transformações diferenciadas em meio aos próprios elementos físicos da paisagem (Schuch, 2006; Bonametti, 2020).

De acordo com Moura (2010) as áreas verdes, além de atuarem positivamente sobre o meio ambiente, como citado em parágrafos anteriores, favorecem a uma maior diversidade biológica no espaço urbano, quando criam um ambiente que oferece abrigo e alimento à fauna urbana; melhora a estética da cidade, quando quebra a rotina da paisagem do concreto e do asfalto; atua de maneira benéfica sobre o psicológico humano num momento de ócio e descanso; cria um ambiente mais agradável para a prática do esporte e do lazer; ajuda a manter a saúde humana, através do relaxamento, da recreação, da prática de esportes e atuando de maneira positiva sobre o pique humano; quebra a monotonia das cidades, introduzindo cores e elementos decorativos no meio do cinza e escuro do concreto e do asfalto; serve de referência e afeição entre os habitantes e sua cidade, que reconhecem e se identificam com as plantas que nela se encontram.

A escola se constitui um espaço que propicia as oportunidades, via horta ou arborização, para que os alunos possam ter papel ativo no processo para obtenção de alimentos mais saudáveis, melhor qualidade de vida e relacionamento com o ambiente natural. A escola também tem um "papel fundamental na modificação dos padrões de comportamento e consumo de alimento das crianças e dos jovens" (Dias, 2003). Para que se possam compreender melhor as relações entre homem e o meio ambiente faz-se necessário o estudo da percepção ambiental, pois esta permite conhecer as expectativas, anseios, satisfação e insatisfação, julgamentos e condutas da coletividade ou dos indivíduos. No mais, cada pessoa percebe, reage e responde diferentemente às ações sobre o ambiente em que vive (Fernandes et al., 2003).

A percepção pode ser definida como o ato de perceber o ambiente no qual o indivíduo está inserido, ou a faculdade de perceber e adquirir conhecimento a partir de algo por meio dos órgãos dos sentidos; ou ainda, a percepção ambiental pode significar uma tomada de consciência do ambiente. Sendo assim, a percepção ambiental abrange a compreensão de como o indivíduo ou a sociedade percebe o seu meio circundante, expressa suas opiniões, expectativas e propõe linhas de conduta (Costa et al., 2012).

A arborização cumpre funções importantes de paisagismo, valorizando a estética local e a beleza cênica. É ainda, um fator que contribui para a diminuição do stress da população urbana e, também, para a valorização da qualidade de vida local. Além disso, propicia equilíbrio ao ambiente natural modificado. Neste aspecto a escola se insere no mesmo contexto (Sabbagh, 2011).

Visto isso, este trabalho teve como objetivo conscientizar os alunos que o plantio de árvores é importante, inclusive no ambiente escolar e na comunidade ao redor da escola, para que se possa haver mais compromisso com o meio que se deparou. 


\section{Metodologia}

\section{1 Área da pesquisa}

O trabalho se desenvolveu no pátio da Escola Estadual de Educação Básica Pedro Joaquim de Jesus, localizada no município de Teotônio Vilela - Alagoas, com alunos do $1^{\circ}$ ano "C" e "D" vespertino, o mesmo foi executado em novembro de 2018.

A pesquisa metodológica foi baseada em Fagundes et al. (2015) que abordam a arborização em ambiente escolar como meio teórico e prático na construção de novos saberes, bem como, de instigar nos alunos o espirito de preservação e organização do espaço escolar, corroborando em uma melhoria da qualidade ambiental no espaço frequentado por eles. Os estudos norteadores da parte experimental foram adaptados de Naves e Brick (2011).

\subsection{Etapas do projeto}

Realizaram-se duas etapas de conhecimento, onde a primeira etapa objetivou-se na interação de alunos e professores com uma aula teórica sobre anatomia e morfologia vegetal. Foram ministradas palestras sobre anatomia vegetal detalhando sua divisão em relação às plantas, raiz, caule, folha e demais classificações, utilizando-se do retroprojetor. Em seguida houve um questionário em roda de conversa com o objetivo de avaliar o conhecimento dos alunos sobre a aula ministrada.

Na segunda etapa do projeto foi utilizado todo o conhecimento adquirido durante as palestras na roda de conversa, para que fosse possível executar a prática estabelecida. Foram divididos 5 grupos de 15 alunos cada, onde cada grupo escolheu um lugar no ambiente da escola para plantar uma árvore. Foram plantadas mudas de acerola (Malpighia emarginata), goiabeira (Psidium guajava) e rabo de camarão (Justicia brandegeeana). Para este momento foram utilizados: 3 mudas de plantas, colher de pedreiro, regadores, água, baldes.

Para finalizar, todos os alunos se reuniram no pátio da escola, onde houve uma conversação sobre a importância do projeto executado, e alguns alunos expôs oralmente para turma o que já sabiam empiricamente sobre a temática e enfatizaram o aprendizado com o projeto trabalhado.

\section{Resultados e Discussão}

Após a palestra, foram realizadas 5 perguntas aos discentes em uma roda de conversa, dessa forma, foi possível analisar o conhecimento sobre a temática e, além disso, foram avaliadas as frequências dos alunos que participaram e responderam aos questionamentos (Figura 1).

Tabela 1: Perguntas feitas aos alunos do $1^{\circ}$ ano do Ensino Médio.

\begin{tabular}{l}
\hline \multicolumn{1}{c}{ Questionário } \\
\hline 1- Quem já plantou uma árvore? \\
2- Qual a importância da arborização? \\
3- Quais os benefícios que as plantas nos proporcionam? \\
4- O que é sustentabilidade? \\
5- Por que devemos plantar árvores?
\end{tabular}

Fonte: Autores (2021). 
Figura 1: Frequência dos alunos que souberam responder ao questionário.

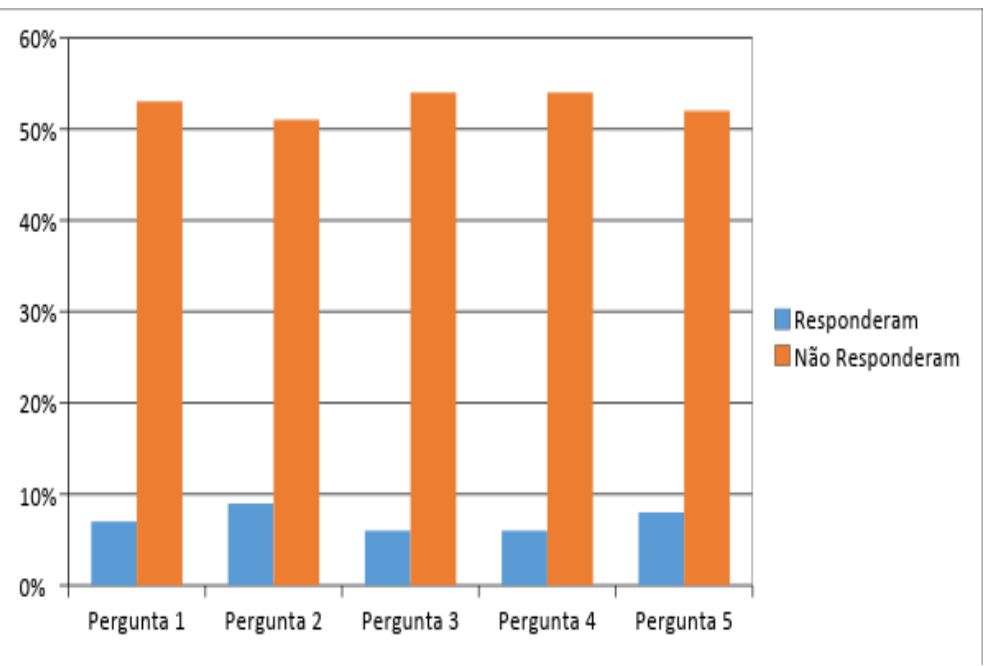

Fonte: Autores (2021).

Com base nas perguntas realizadas no início da conversação foi possível constatar que o conhecimento dos alunos sobre a importância da arborização, os benefícios e as responsabilidades com as mesmas eram básicos. A arborização urbana caracteriza-se como um dos elementos mais importantes que compõem o ecossistema das cidades, sendo que parte dessa arborização envolve as praças da cidade e locais turísticos. O município de Icapuí é uma cidade localizada no extremo leste do Ceará e é distribuído ao longo de uma planície costeira que apresenta temperaturas altas o ano todo. Espaços públicos como praças são uma das alternativas para proporcionar o bem-estar da população em geral (Júnior et al., 2020)

Ao longo da realização do projeto, após a conversação observou-se que a concepção dos alunos com relação a importância das plantas mudou, mesmo tendo uma baixa frequência de respostas. Percebeu-se a mudança no conhecimento sobre a temática, o aprofundamento e maior entendimento sobre os assuntos, através das respostas após a palestra por parte de alguns alunos, sendo assim de fundamental importância trabalhar essa temática com jovens que já estão formando uma concepção real de mundo.

Acredita-se, assim como Mortimer (2000), que a aprendizagem ocorre por meio do envolvimento ativo dos alunos na construção do conhecimento e que suas ideias prévias desempenham um papel importante no processo de aprendizagem. Destaca a importância de se buscar uma cidade viva, segura, sustentável e saudável, e o espaço público de qualidade tem uma importância fundamental. Segundo o autor, as árvores e o paisagismo desempenham um papel fundamental no espaço urbano, elas fornecem sombra e são elementos importantes para refrescar e limpar o ar (Gehl, 2015).

De acordo com Vasconcellos (1997), promover a mentalização dos discentes com a relação ao assunto, os fazem perceber a ligação que existe entre seres vivos de um modo geral e o meio ambiente, causando assim uma dependência entre as duas partes.

Foi realizado uma palestra sobre a Importância das plantas e roda de conversa com os alunos, onde puderam tirar suas dúvidas em relação aos cuidados, importância do plantio para a saúde e preservação do ecossistema. Muitas dúvidas houveram, e muitos conhecimentos foram aprendidos diante as informações levadas.

Os alunos entenderam que a natureza e a saúde humana necessitam de árvores e plantas para sobreviver num mundo no qual a industrialização perpassou o espaço global, porém, cabe-nos a tentar reverter esse quadro, fazendo cada um à sua parte e não deixar morrer a arborização. Quando se substitui a vegetação por asfalto, favorece a absorção de radiação solar diurna e a reflexão noturna, formando o fenômeno "ilhas de calor". A pavimentação e as construções ocupam o lugar da vegetação que não é replantada e, devido à ausência de áreas verdes, gera desconforto na ambiência urbana (Mascaró, 2010) 
Constatou-se ao longo do desenvolvimento do projeto que é de suma importância a compreensão dos alunos a respeito da arborização do ambiente, os benefícios que uma árvore traz para a vida de modo geral, por meio dos frutos, da madeira utilizada para a fabricação de móveis e casas, por purificar o ar além da ornamentação.

Após as aulas teóricas, foram realizadas as práticas, onde foram plantadas mudas de acerola (Malpighia emarginata), goiabeira (Psidium guajava) e rabo de camarão (Justicia brandegeeana) (Figura 2). A utilização de espécies nativas, estas que são adaptadas às condições de clima e solo regionais, auxilia a construir uma área semelhante a natural, sendo também uma forma de divulgação e valorização da flora local e contribui para a manutenção da biodiversidade da Caatinga (Alvarez et al., 2012)

Figura 2. Transplante de mudas pelos alunos.

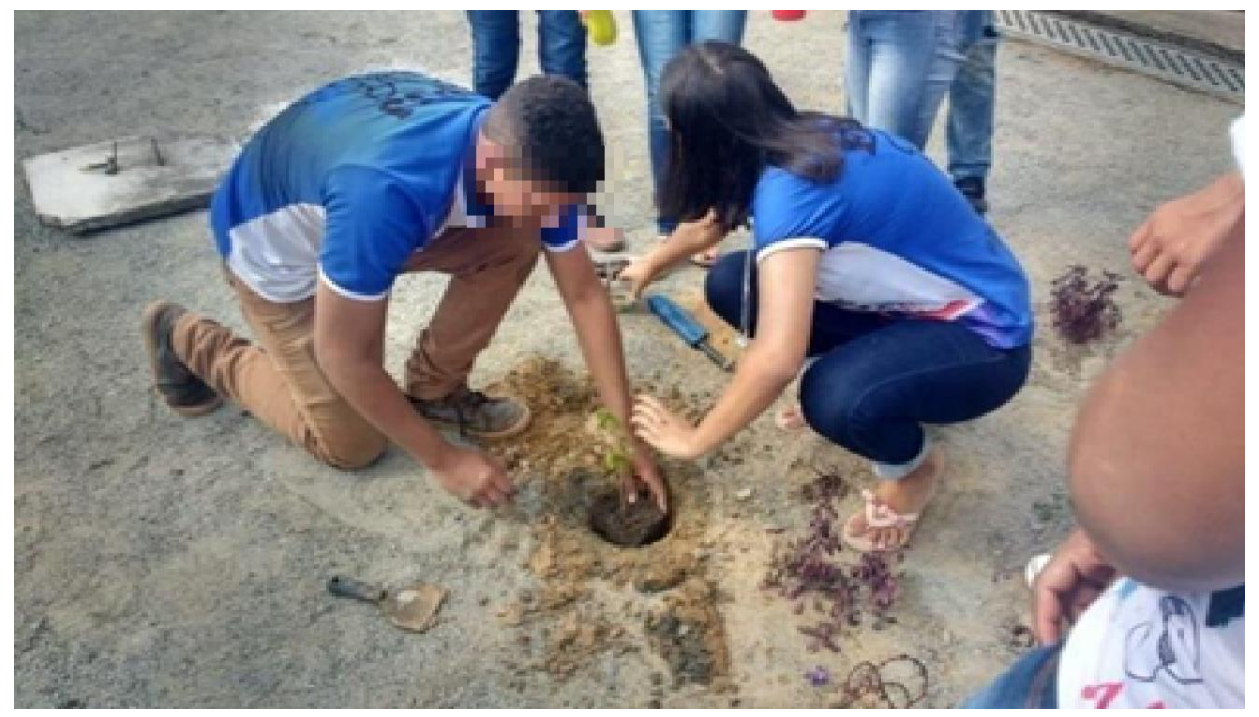

Fonte: Autores (2018).

Foi executada fora da sala de aula, no pátio da escola, selecionados 45 alunos, em três grupos de 15, desta forma fazendo com que cada grupo ficasse com uma muda; depois de separado, cada grupo procurou o melhor local para plantar a sua plântula, de acordo com as instruções que foram passadas nas palestras anteriores. Depois de encontrar o local para sua muda, os grupos se organizaram para que cada componente pudesse participar desse processo, uns foram pegar água, outros cavaram, seguindo uma organização, como mostra as figuras 5 e 6.

A vegetação auxilia na minimização dos efeitos da ilha de calor, pois utiliza a radiação solar no processo de fotossíntese o que ajuda na diminuição da temperatura e da umidade relativa do ar, reduzindo a poluição atmosférica. A vegetação de porte arbóreo é um excelente filtro para poluentes urbanos e partículas finas, esta vegetação absorve gases poluentes (tais como: monóxido de carbono, óxidos de nitrogênio e ozônio) e filtra partículas finas como: poeira, sujeira ou fumaça do ar, prendendoos em folhas e casca, também atua em favor da redução das emissões de carbono, sendo este um dos gases responsáveis pelo efeito estufa (FAO, 2016). A arborização também contribui na modificação da velocidade e direção dos ventos, abafa ruídos, coopera no combate a erosão, serve de abrigo e alimento para as aves, e como ambiente de lazer para os moradores (Alves et al.,2013).

Segundo Duarte et al. (2017), é muito importante frisar os danos que causam a ausência de arborização, como forma de conscientização, os autores afirmam que as consequências negativas da falta de vegetação no meio urbano desencadeiam no aumento da impermeabilização do solo, aumento da poluição do ar pela queima de combustíveis fósseis, aumento dos riscos de enchentes, aumento no consumo de energia, desvalorização imobiliária, inundações e, por conseguinte, perdas na qualidade ambiental urbana. 
Logo, a ciência tem mostrado a importância das árvores em ambientes urbanos que, por meio de seus serviços ecossistêmicos, fornecem qualidade de vida à população. Dito isto, inúmeras pesquisas têm apontado para importância das árvores em ambiente urbanos, que por meio de seus serviços ecossistêmicos, proporcionam mais qualidade de vida (Santos et al., 2021).

Figura 3. Preparação da terra para o plantio das mudas.

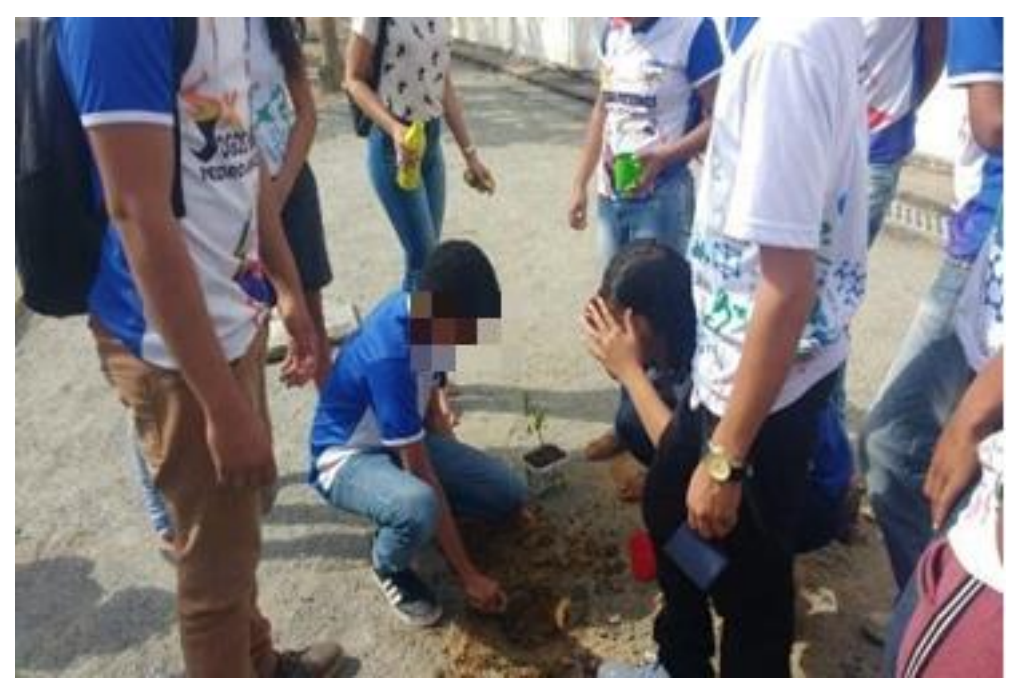

Fonte: Autores (2018).

Figura 4. Plantação das mudas.

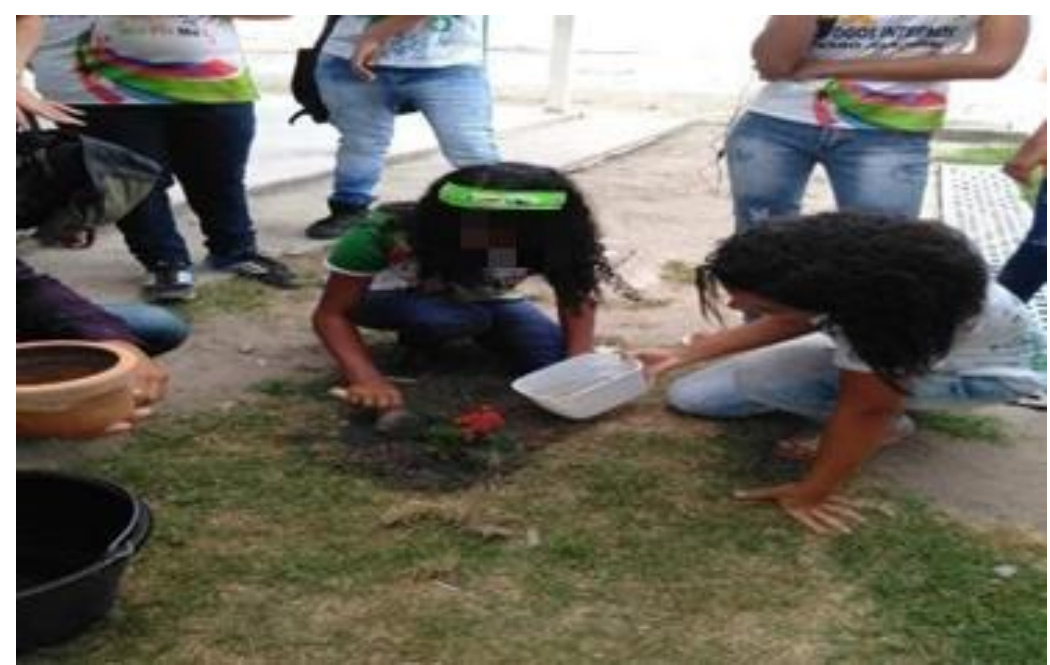

Fonte: Autores (2018).

Depois do processo de cavar e preparar a terra com água, os alunos plantaram a muda (como mostra nas imagens da figura 5 e 6) e tiveram todo um cuidado para certificar que a planta não seria esmagada por outros alunos, colocando pedras em volta da plântula, logo depois desse processo, todas as esquipes foram chamadas para o refeitório para que pudessem finalizar o projeto com as informações finais que eles teriam uma responsabilidade de cuidar daquela muda, fornecendo insumos necessários para o seu desenvolvimento, posteriormente foi feito o agradecimento de toda equipe, pela colaboração e dedicação dos alunos para que o projeto pudesse ser executado.

O Ministério da Educação considera importante que se estabeleça novos modelos educacionais onde integrem saúde, meio ambiente e desenvolvimento comunitário por meio de programas interdisciplinares. Para atingir essas metas a horta escolar 
e a relação desta com a participação comunitária se torna um eixo articulador com ricas possibilidades de atividades pedagógicas (Fernandes, 2003).

\section{Conclusão}

A experiência sobre conhecimento do alunado diante da temática sobre a importância das plantas no meio em que eles convivem, está relacionando com a saúde do homem, ressaltando o cuidado de onde e como plantá-las, no qual pôde-se conscientiza-las no cuidado e manutenção da planta durante seu período de desenvolvimento, transmitindo, no entanto, a responsabilidade de preservação da relevância para o meio ambiente e saúde humana.

Além disso, foi perceptível o interesse, o aprendizado e a participação de alguns alunos através de um momento em que relataram a experiência vivenciada, subjetivando seus conhecimentos empíricos com os que adquiriram nesta pesquisa.

\section{Referências}

Alvarez, I. A. et al. (2012). Arborização urbana no semiárido: espécies potenciais da Caatinga. Colombo: Embrapa Florestas.

Alves, A. C. N.; Andrade, T. C. Q.; Nery, J. M. F. G. (2013). A influência da vegetação e da ocupação do solo no clima urbano: um exercício analítico sobre a Avenida Paralela. Fórum Patrimônio: Ambiente Construído e Patrimônio Sustentável, v.4, n. 1, p. 1-9.

Avrella, E. D., Weiller, E. B., Silva, A. C., HiguchI, P. (2014). Avaliação quantitativa da arborização urbana de praças e vias públicas. Revista de Ciências Agroveterinárias, Lages, v.13, n.3, p.2.

Bonametti, J. H. (2020). Arborização urbana. Revista Terra \& Cultura: Cadernos de Ensino e Pesquisa, v. 19, n. 36, p. 51-55.

Costa, J. R. et.al. (2012). Metodologia de Ensino: A percepção ambiental do corpo docente de uma escola pública rural em Manaus. https://editorarealize.com.br/revistas/conedu/trabalhos/trabalho_ev056_md1_sa10_id8716_02082016000436.pdf.

Dias, G. F. (2003). Educação ambiental: Princípios e práticas.

https://editorarealize.com.br/revistas/conedu/trabalhos/TRABALHO_EV056_MD1_SA10_ID8716_02082016000436.pdf.

Duarte, T.E.P.N. et al. (2017). Arborização urbana no Brasil: um reflexo de injustiça ambiental. Revista Terr@Plural, v. 11, n. 2, p. 291-303.

Fagundes, J. F., Bandeira, G. L., Siqueira, A. B., Neis, F. A., \& Konflanz, T. L. (2015). Arborização e jardinagem na escola municipal de ensino fundamental Assis Brasil em Palmeira das Missões-RS. Revista Eletrônica em Gestão, Educação e Tecnologia Ambiental. Santa Maria, RS. Vol. 19 , n. 2), p. 1162-1173.

Fernandes, R.S. et.al. (2003). Educação ambiental: Uso da percepção ambiental como instrumento de gestão em aplicações ligadas às áreas educacional, social e ambiental. Disponível em: https://editorarealize.com.br/revistas/conedu/trabalhos/TRABALHO_EV056_MD1_SA10_ID8716_02082016000436.pdf.

Frigeri, J. V., Krefta. S. M., Paula, A. S., Germano, A. D., Krefta, S. C. (2017). Benefícios ambientais e socioeconômicos da arborização urbana. Revista Uniplac. rLAS® v.2, n.1.

Gehl, J. (2015). Cidades Para Pessoas. 3 eds. São Paulo: Editora Perspectiva.

Júnior, F. V. L. O. et al. (2020). Quantitative and qualitative diagnosis of the afforestation of a public square and a belvedere in the municipality of Icapuí-CE. Brazilian Journal of Development, v. 6, n. 8, p. 586.

Mortimer, E. F. (2000). Linguagem e formação de conceitos no ensino de ciências. UFMG.

Moura, I. R. (2010). Arborização Urbana: Estudo das praças do bairro centro de Teresina. Dissertação. Rio Claro, SP, p. 7.

Mascaró, L; Mascaró, J. (2010). Vegetação Urbana. 3.ed. Porto Alegre: Mais Quatro editora. 240p.

Naves, C. R., \& Brick, V. D. S. (2011). Análise quantitativa e qualitativa do nível de conhecimento dos alunos do curso de fi sioterapia sobre a atuação do fisioterapeuta em saúde pública. Ciência \& Saúde Coletiva, 16, 1525-1534.

Organização das nações unidas para alimentação e agricultura (FAO). (2016) FAO no Brasil. http//:www.fao.org/brasil/pt/.

Sabbagh, R. (2011). Arborização escolar: Arborização urbana no Bairro Mario Dedini em Piracicaba.

Santos, G. L. et al. (2021). Arborização urbana e Educação Ambiental: estudo de caso com o evento "Arboriza Ponta Grossa.” Research, Society and Development, v. 10, n.10, p. e79101018332.

Schuch, M. I. S. (2006) Arborização Urbana: Uma contribuição à qualidade de vida com uso de geotecnologias. Dissertação de Mestrado. Santa Maria, RS.

Vasconcellos, H. S. R. A. (1997). pesquisa-ação em projetos de Educação Ambiental. In: PEDRINI, A. G. (org). Educação Ambiental: reflexões e práticas contemporâneas. Petrópolis, Vozes. Educação Ambiental. http://www.suapesquisa.com/educacaoesportes/educacao_ambiental.htm. 